\title{
https://doi.org/10.30853/manuscript.2019.7.29
}

\section{Акшенцева Вероника Михайловна}

\section{ИНСТРУМЕНТАЛЬНЫЕ КОНЦЕРТЫ Й. ГАЙДНА В КОНТЕКСТЕ МЕЖЖАНРОВЫХ}

\section{ВЗАИМОДЕЙТВИИ}

В статье рассматриваются процессы формирования инструментальных концертов Й. Гайдна в культурологическом контексте. Становление тембрового и количественного инструментального компонента изучается в тесной связи с практикой музицирования того времени. Освещаются межжанровые взаимодействия, а также социокультурные аспекты, повлиявшие на развитие жанра. Среди них музыкальное просветительство, исполнительский дилетантизм, расцвет досуговой культуры и др. Кристаллизация инструментальных групп гайдновских концертов исследуется в преемственности ансамблевому интонированию и концертированию, сложившимся в трио-сонате и concerto grosso. В работе изучаются и классифицируются инструментальнооркестровые составы концертов Й. Гайдна.

Адрес статьи: www.gramota.net/materials/9/2019/7/29.html

\section{Источник}

\section{Манускрипт}

Тамбов: Грамота, 2019. Том 12. Выпуск 7. С. 140-144. ISSN 2618-9690.

Адрес журнала: www.gramota.net/editions/9.html

Содержание данного номера журнала: www.gramota.net/materials/9/2019/7/

\section{() Издательство "Грамота"}

Информация о возможности публикации статей в журнале размещена на Интернет сайте издательства: www.gramota.net Вопросы, связанные с публикациями научных материалов, редакция просит направлять на адрес: hist@gramota.net 


\title{
Музыкальное искусство
}

\author{
Musical Art
}

УДК 78.072.2

https://doi.org/10.30853/manuscript.2019.7.29

Дата поступления рукописи: 27.03.2019

В статье рассматриваются проиессы формирования инструментальных кониертов Й. Гайдна в культурологическом контексте. Становление тембрового и количественного инструментального компонента изучается в тесной связи с практикой музииирования того времени. Освещаются межжанровые взаимодействия, а также социокультурные аспекты, повлиявшие на развитие жанра. Среди них музыкальное просветительство, исполнительский дилетантизм, расивет досуговой культуры и др. Кристаллизация инструментальных групп гайдновских концертов исследуется в преемственности ансамблевому интонированию и концертированию, сложившимся в трио-сонате и concerto grosso. В работе изучаются и классифицируются инструментально-оркестровые составы концертов Й. Гайдна.

Ключевые слова и фразы: концерт; музицирование; жанр; инструментальный состав; межжанровые взаимодействия; оркестр; принципы концертирования; инструментальный колорит.

\section{Акшенцева Вероника Михайловна \\ Магнитогорская государственная консерватория (академия) имени М. И. Глинки veronikaakshenceva2010@mail.ru}

\section{ИНСТРУМЕНТАЛЬНЫЕ КОНЦЕРТЫ Й. ГАЙДНА В КОНТЕКСТЕ МЕЖЖАНРОВЫХ ВЗАИМОДЕЙСТВИЙ}

Многочисленные инструментальные концерты Йозефа Гайдна органично вписываются в контекст классической эпохи. Композитор обращался к этому жанру на протяжении сорока лет (1756-1796). В 1756 году двадцатичетырёхлетним музыкантом в Вене был создан первый образец жанра - Конщерт для органа (клавира) с оркестром C-dur (Hob XVIII:1), а в 1796 году последний - Концерт для трубы с оркестром Es-dur (Hob VIIe:1), написанный под влиянием дружбы с блестящим трубачом А. Вайдингером, виртуозно владевшим клапанной трубой. Сведения о нумерации концертов здесь и далее приводятся в опоре на каталог нидерландского учёного А. Хобокена [10].

Несмотря на то, что инструментальное творчество Й. Гайдна неизменно пользуется интересом у отечественных музыковедов ${ }^{1}$, его концерты всё ещё находятся на периферии исследовательского интереса. Существующие на сегодняшний день работы сосредоточены преимущественно на жанрах сонаты, камерного ансамбля и симфонии. Вместе с тем в музыкознании, на наш взгляд, остаётся целый блок нерешённых проблем, связанных с изучением процессов формирования инструментальных компонентов концертов Й. Гайдна в контексте практики музицирования того времени. Преемственная предшествующему периоду, она во многом повлияла на выбор ансамблево-оркестровых составов и солистов, становление баланса между ними, внимание к тембровой стороне. В этой связи постижение их специфики в концертной практике второй половины XVIII века особенно актуально в настоящее время, поскольку условия музицирования давно изменились и требуют пристального исследования и аргументированного научного разъяснения.

Целью данной статьи является рассмотрение особенностей межжанровых взаимодействий в связи с формированием и кристаллизацией родовых для концерта принципов, становлением инструментального мышления Й. Гайдна. Изучение ансамблево-оркестровых составов гайдновских концертов в контексте исторического становления жанра под влиянием социокультурных явлений до сих пор не предпринималось в отечественном музыкознании.

В статье впервые осуществляется попытка раскрыть количественно-тембровую компоненту циклов композитора и провести дифференциацию их ансамблево-оркестровых составов. В этой связи необходимо

\footnotetext{
${ }^{1}$ См., к примеру, «Стилевые особенности клавирных сонат Й. Гайдна» Н. М. Смирновой; «Камерные клавирные сонаты Й. Гайдна 1780-х - 1790-х годов: жанровые и стилевые взаимодействия» Е. А. Ткаченко; «Интонационная лексика образов пасторали в тематизме фортепианных сонат Й. Гайдна» А. И. Асфандьяровой; «Артикуляция в клавирных сонатах Й. Гайдна» Э. Э. Черныш; «Клавирные трио Йозефа Гайдна в контексте игрового пространства-времени» А. Л. Хохловой; «Оркестровое письмо раннего Гайдна (на материале симфоний 1757-1774 годов)» А. К. Демидовой.
} 
проследить за их соотношением в концертах венского классика (в разные годы творчества) и в сочинениях композиторов раннеклассического периода, а кроме того, рассмотреть индивидуальные инструментальные предпочтения Й. Гайдна.

Обильные по численности и разнообразные по содержанию концерты Й. Гайдна, с одной стороны, стали продолжением оркестрово-симфонического творчества, а с другой - результатом органичной эволюции дивертисментной традиции в музыке того времени. В представлении музыкантов классического периода, инструментальный концерт занимал промежуточное место между «серьёзными» жанрами, такими, как крупные симфонические циклы, и развлекательными, зрелищными. Кроме того, «уподобление инструмента певческому голосу», по словам Л. В. Кириллиной, «провоцировало ассоциации с оперой, как в сфере выразительности, так и в сфере конкретных музыкальных форм и исполнительских приёмов» [7, с. 324]. Среди сочинений, созданных композитором для различных инструментальных составов, наблюдаются образцы малых и крупных жанров, в которых шлифовались родовые для концерта принципы солирования и ансамблевого со-интонирования.

Так, в жанрах бытового музицирования - маршах, танцах, кассациях, скерцо, пьесах, дивертисментах, по мнению А. К. Демидовой, ансамблевое письмо часто демонстрировало присутствие экспериментов, неожиданных тембровых сочетаний в инструментарии, который этим в значительной степени отличался от оркестрового состава ранних симфоний [4, с. 12]. Названные жанры достаточно тесно взаимодействовали друг с другом, обусловливая вариативность партий ансамбля, мобильность и открытость музыкального текста.

В вокально-хоровых жанрах - мессах, ораториях, кантатах, а также операх и музыке к спектаклям у Й. Гайдна формировалась драматургически значимая и в то же время прикладная функция оркестра. В каждой из месс венский классик находил индивидуальные композиционные и инструментальные решения, ведущая роль в которых принадлежала оркестровым средствам. Их гибкое использование зачастую, по мнению П. А. Вульфиуса, предвосхищает «не только творчество Бетховена, но и композиторов-романтиков» [3, с. 880].

В ораториальном творчестве Й. Гайдна вызревает интерес к качеству звучания инструментов, лежащего в основе принципа концертного солирования. Оно во многом является продолжением риторической семантичности барочного музыкального мышления и отражается в пристальном внимании к тембровой стороне составов, поиску баланса звучания. Весомость инструментальных разделов, разнообразие приёмов оркестровки, техническая сложность сольных партий, тщательная проработка голосов фактуры также свидетельствуют о большом значении принципов концертности в ораториальном творчестве. Серьёзное внимание композитор уделяет инструментовке, обострённо чувствуя звучание каждого участника оркестра. При этом, как и в гайдновских концертах, наиболее ярко использование индивидуальных красок проявляется в композиционно и драматургически значимых сегментах текста. В этом смысле увеличение и стабилизация исполнительского аппарата, чёткое разграничение оркестровых групп, тонкая тембровая детализация, характерные для инструментализма ораторий Й. Гайдна, проявляются со всей очевидностью в его концертах. Так, в них композитор широко использует уже сложившиеся в ораториальном творчестве тембровые амплуа инструментов. Среди них выразительные функции инструментальных клише, сформировавшихся в тесной связи со словом и сценическим действом. К примеру, как отмечает исследователь Л. Ю. Аристархова, в оратории «Возвращение Товия» венский классик отображает «дрожание моряка» (“tremo il nocchiero") катящимися волнообразными пассажами скрипок, а «сельский колорит при появлении пахаря (“Geme talora l'agricoltore” - "Порою стонет крестьянин”) создаётся прелестным в своей деревенской наивности соло гобоя» [1, с. 115]. Взаимозависимость вербально-смыслового и звукового рядов в трактовке инструментальных тембров ораторий раскрывается, например, посредством включения тромбона и других духовых для изображения моментов общения героев с Богом, а также группы струнных в высоком регистре, символизирующих обращение к небесному [Там же, с. 76, 115]. В сочинениях, предназначенных для церкви, Й. Гайдном часто вводятся в оркестровую партитуру трубы и литавры.

Общими для ораторий и концертов являются многообразные методы тематической работы, а также принцип симфонизма. Они уравновешивают многомерность и разнообразие, свойственные художественным концепциям поздних ораторий и ряда концертов венского классика.

Инструментальный концерт, взаимодействуя с оперой, вбирает лучшие достижения этого жанра. Несмотря на сопровождающую роль оркестра, его партитура уже в операх раннего периода имеет раннеклассический состав ${ }^{1}$, который утверждается и в концертах. Кроме того, для обоих в равной степени свойственен принцип выключения тутти при проведении партии солистом, будь то голос или инструмент. Так, в опере туттийное оформление оркестровых ритурнелей сменяется «скромным» ансамблем при вступлении вокальной партии, причём в некоторых номерах пара гобоев может отсутствовать и заменяться парой флейт. Такая взаимозаменяемость инструментов в оркестре является отражением практики музицирования, для которой были характерны мобильные составы. А инструментовка сопровождения в медленных частях концертов Й. Гайдна напоминает оркестровые партитуры оперных речитативов, использующих в аккомпанементе двухголосие струнных с поддержкой аккордов continuo.

Наиболее интенсивно на развитие ансамблево-оркестрового мышления в концертах повлияли жанры инструментально-симфонической музыки (увертюра, симфония и др.). Неистощимая изобретательность, находчивость,

\footnotetext{
${ }^{1}$ Оркестры классической эпохи, с присущими им принципами оркестровки, отечественное музыкознание разделяет на два типа - раннеклассический (1740-80-е годы) и классический (1780-1815) [4, с. 13]. Промежуточным звеном между разнообразием оркестровых объединений эпохи барокко и установившимся парным составом классицизма является раннеклассический оркестр, в котором намечается тенденция к утверждению постоянного состава.
} 
применение «ритмических и динамических “сюрпризов”, обостряющих движение и заставляющих внимание слушателей быть всегда настороже», характерные, по мнению Б. В. Асафьева для симфоний Й. Гайдна, в равной степени могут быть отнесены к его концертам [2, с. 11]. Аналогично ранним симфониям, в циклах наблюдаются различные составы раннеклассического оркестра, от более «сокращённого» (без гобоев или без валторн) до «расширенного», включающего одну или две флейты, вторую пару валторн. Внимание к инструментальному колориту, объединение и поиск баланса индивидуальных тембров различных инструментов с их специфическими звуковыми красками становятся общим принципом для оркестровых и концертных сочинений. Для них одинаково актуальным является инструментальная «персонификация» отдельного инструмента в сочетании с искромётным и «артистичным» звучанием всего оркестра. Присущие симфониям «инструменты - живые фигуры с характерными жестами, тембром голоса и отличительной “походкой”» [Там же, с. 10] - проявляют себя ещё с большей очевидностью в концерте.

Тематизм концертов, сонат и симфоний отличают яркость и рельефность, индивидуализированность и пластическая выразительность инструментальной речи. Как отмечает Л. В. Кириллина, иерархия тембров в оркестровых симфониях соблюдалась достаточно строго. Отношение композитора к медным духовым инструментам эволюционирует на протяжении всего симфонического творчества, от полного отсутствия этой группы в ранних образцах и редкого применения в сочинениях, приуроченных к празднествам и торжествам, до повсеместного включения труб и литавр в поздних произведениях [7, с. 251]. Формирование органологической специфики инструментов в процессе их развития, становление их функционально-атрибутивных характеристик в сольной и ансамблево-оркестровой концертной практике, исполнительские традиции и многое другое обусловили число обращений композиторов эпохи классицизма в целом и Й. Гайдна в частности к определённым инструментам. Солистами концертов венского классика становятся как занимающие в исполнительской практике лидирующие позиции клавир (орган) и скрипка, так и редко используемые лира, баритон.

Обращаясь к инструментальным составам гайдновских концертов, можно отметить преимущественное использование камерных объединений. Как известно, во второй половине XVIII века ансамблевые коллективы, численность которых составляла половину от всех оркестров Европы, функционируют параллельно с большими оркестрами. Мобильные и скромные по количеству участников камерные составы обладали возможностями тонкой графической «прорисовки» партий, с одной стороны, и ярким выделением партии солиста - с другой. В этом смысле они, продолжая традиции барочной ансамблевой музыкальной культуры, способствовали утверждению классического «канона». Кроме того, обращение композиторов к «сокращённым» составам способствовало интенсивному формированию и более динамичному обновлению репертуара. Вместе с тем достаточно определённо намечается тенденция к некоторому увеличению численности инструментов в оркестре, поиску их индивидуальных тембровых возможностей и различных сочетаний, которые происходят одновременно с кристаллизацией композиционных и драматургических особенностей жанра концерта.

Здесь Й. Гайдн опирается на уже сложившиеся к тому времени составы ансамблей в трио-сонатах ${ }^{1}$ и concerto grosso, в которых аккумулируются главные достижения эпохи в области инструментальной музыки. По мнению А. В. Епишина, «именно трио-соната стала одним из старейших и существенных истоков западноевропейского предклассического и классического инструментализма - камерного и симфонического» [6, с. 22]. Являясь своего рода «мостом» между двумя противоположными системами мышления - полифонической и гомофонно-гармонической, трио-соната закладывает основы для формирования новых жанров, таких, как сольные концерты, сонаты с сопровождением, щипковые трио. Универсальный барочный трио-принцип, объединяющий инструментальные и вокальные жанры, подчиняет себе фрагменты больших ансамблей и ассимилируется в концертах и сонатах, сюитах и увертюрах Й. Гайдна.

Предшествующий классическому концерту жанр concerto grosso избирает в качестве одного из исполнительских аппаратов камерный оркестр, становление которого произошло к концу XVII века ${ }^{2}$. Именно от concerto grosso классический концерт заимствует небольшой состав, индивидуализацию тембров, голосов и исключительную роль каждого исполнителя - в группе concertino, унисонные объединения в партиях групп ripieno. Как отмечает Э. М. Прейсман, такие тенденции прослеживаются уже в concerto grosso А. Вивальди, где индивидуализация тематизма и тембров солирующих инструментов «выходит на новый качественный уровень - кристаллизацию жанра концерта для солирующего инструмента с оркестром» [8, с. 23].

Концертами Й. Гайдна были восприняты сложившиеся в concerto grosso дифференциация ансамблевооркестровых групп - concertino (две скрипки и виолончель) и ripieno (первые и вторые скрипки, альты, басы), индивидуализация тематизма. При этом камерные оркестры (ансамблево-оркестровые «инструментальные объединения» Э. М. Прейсман [Там же, с. 15]) положили начало возникновению жанров, «становление

\footnotetext{
${ }^{1}$ В одном из ведущих жанров XVII-XVIII веков в трио-сонате отшлифовался ансамблевый состав, обычно содержащий три инструмента (партии). Он включал два голоса сопрановой тесситуры (скрипки, позднее цинки, виолы да браччо, гобои, продольные и поперечные флейты) и бас (виола да гамба, виолончель, реже фагот, тромбон). Функция basso представлялась композиторами и как одноголосная (сольная), и как развёрнутая basso continuo, исполняемая теорбой, китарроном, клавесином или органом.

2 Для ансамблевого жанра concerto grosso характерен принцип «светотени», яркие контрасты между небольшой группой солирующих инструментов - concertino и общей ансамблевой массой ripieno, благодаря которому отражались барочные представления о пространстве и времени. Первые образцы были написаны для струнно-смычкового ансамбля, а в процессе развития жанра начали вводиться духовые инструменты - флейта, гобой, труба, валторна. Такой расширенный состав стал непосредственным предшественником классического симфонического оркестра.
} 
которых неразрывно связано с формированием инструментальных исполнительских аппаратов» [Там же]. Истоки названных процессов, протекающих в концертах Й. Гайдна, восходят к принципам инструментального мышления, отшлифовавшимся в различных жанрах музыки барокко.

Вместе с тем поиск нового осуществляется в русле складывающихся закономерностей становления музыкальной культуры классической эпохи. В значительной степени это относится и к выбору инструментария, его количественной компоненте, а также особенностям оркестрового письма.

Как уже отмечалось, камерность ансамблево-оркестровых составов, принципы инструментовки сочинений позднего барокко ${ }^{1}$ органично подготовили характерный для раннеклассического оркестра состав в виде двух скрипок, альта, басовой группы, двух гобоев, двух валторн. Только с 1790-х годов стабилизация оркестровых групп приводит к формированию общепринятого классического парного состава: струнная группа (первые скрипки, вторые скрипки, альт, виолончель, контрабас), две флейты, два гобоя, два кларнета, два фагота, двечетыре валторны, две трубы, тромбоны. Вместе с тем, как отмечает А. К. Демидова, лишь пять из ста шести симфоний Гайдна (№ 99, 100, 101, 103, 104) были написаны с расчётом на такой оркестровый состав [4, с. 43].

Духовые инструменты приобретают большую самостоятельность. Формируется трёх-четырёхголосие в соотношении партий струнной группы, функция basso continuo в оркестре постепенно изживает себя. Мобильная инструментовка в это время постепенно становится неотъемлемым компонентом музыкальной композиции и драматургии.

Названное отражается в нотографической фиксации инструментальных партитур, запись которой унифицируется, обретая точность, завершённость и постоянство. Устанавливаются определённые взаимосвязи между характером изложения каждой партии и возможностями инструмента, для которого она предназначена. Одним из признаков завершения раннеклассического периода с точки зрения оркестрового письма, по мнению А. К. Демидовой, является возникновение в гайдновских партитурах с 1774 года отдельной строки для партии фагота на месте, которое в настоящее время стало закономерным [Там же, с. 23].

Вместе с тем не менее важным в формировании инструментального концерта Гайдна является значение собственно практики музицирования, связанной со светской культурой. Социальная ситуация, сложившаяся в XVII - начале XIX века, благоприятствовала распространению музыкального дилетантизма ${ }^{2}$. Он был напрямую связан с музицированием и в значительной степени повлиял на увеличение количества исполнителей-профессионалов. В это время, по словам Е. В. Дукова, музыкальный мир разделяется на три направления: «...профессиональных музыкантов - тех, кто сочиняет и зарабатывает себе на жизнь исполнительской деятельностью, любителей, “дилетантов” - тех, кто исполняет музыку, но зарабатывает себе на хлеб вне искусства, и знатоков - тех, кто о музыке судит» [5, с. 215]. В этой связи расцвет досугового музицирования и концертной практики был во многом обусловлен расширением круга просветительских сообществ - коллегий, академий, музыкальных собраний и т.п. Неоценимым в этом процессе стала роль музыкального образования, где проходили деятельность выдающихся личностей и развитие нотопечатания.

На ансамблево-оркестровый состав гайдновских концертов, очевидно, повлиял и такой фактор, как имеющийся в распоряжении композитора действующий оркестр. Так, в период с 1757 по 1760 гг. Й. Гайдн занимал пост директора музыки при дворе Фердинанда Максимилиана Франца Морцина. Предположительно капелла графа Морцина насчитывала 12-16 музыкантов ${ }^{3}$. А находясь на службе у П. А. Эстергази, с 1761 года венский классик руководил составом из 4-5 скрипок, альта, виолончели, контрабаса, 2-х гобоев, 2-х фаготов - всего около 12 исполнителей. Такой инструментарий в распоряжении Й. Гайдна сохранялся до 1766 года. В результате переезда композитора и музыкантов в Эстергаз произошло увеличение оркестра (по сравнению с предыдущим составом) до 25 человек. Предоставленный коллектив венский классик использовал в своём концертном и симфоническом творчестве. Однако, вне зависимости манеры письма от обстоятельств созданий произведений, для концертного творчества Й. Гайдна характерны мобильность составов и инструментального стиля в целом. К примеру, наряду с образцами симфоний с развёрнутыми солирующими партиями, продолжают создаваться сочинения для традиционного раннеклассического состава, без ярких, необычных сольных сегментов. По мнению Э. М. Прейсмана, все сочинения этого жанра (№ 3-31), возникшие с 1761 по 1766 гг., в большей степени являются камерно-оркестровыми произведениями [8, с. 39].

Создание Й. Гайдном произведений в различных жанрах, в том числе концертов, с использованием разнообразных инструментальных составов, с одной стороны, отражает общую тенденцию мобильности составов раннеклассического периода, а с другой - свидетельствует об активных поисках и экспериментах композитора в области инструментовки. Во многом этому способствовали разнообразные благоприятные обстоятельства, в том числе профессиональные и материально-бытовые.

\footnotetext{
${ }^{1}$ Одним из наследий барочного письма в раннеклассическом оркестре Й. Гайдна является принцип “colla parte”, предполагающий вариативность тембрового звучания какой-либо партии (возможность исполнителю играть по партии другого инструмента).

2 Понятие «дилетант» в музыкальной культуре Германии и Австрии XVIII века, по словам А. А. Шакирьяновой, не наделяется «пренебрежительной коннотацией», а предполагает благородную и высокую деятельность личности [9, с. 19].

3 Сведения о составе коллектива не сохранились, поэтому выводы опираются только на косвенные источники, к примеру, написанные в этот период партитуры симфоний. Однако сложность, как отмечает А. К. Демидова, заключается в том, что ни одна симфония «до-эстергазиевского» периода не была найдена в виде автографа, только в виде рукописных копий [4, с. 59]. Раннеклассический состав капеллы был мобильным. Количество струнных варьировалось от трёх-четырёх первых скрипок, трёх-четырёх вторых скрипок, одной виолончели, одного контрабаса с возможным добавлением фагота. Иногда в оркестр добавлялись трубы и литавры, чтобы подчеркнуть праздничный характер музыки.
} 
Так, по количественно-тембровым компонентам в концертах композитора можно обозначить несколько ансамблево-оркестровых составов. Вне зависимости от разных нюансов, во всех образцах задействовано скрипичное семейство, ставшее незыблемой основой классического оркестра в XVIII веке. При этом Й. Гайдн использует не только традиционный квартет, включающий в себя скрипку, альт, виолончель, контрабас, но прибегает и к более лаконичному составу струнных - без участия альта. Инструментальные объединения в виде двух скрипок и баса встречаются в концертах для клавира с оркестром F-dur (Hob. VIII:7); G-dur (Hob. XVIII:9); C-dur (Hob. XVIII:10); F-dur (Hob. XVIII:F2), для баритона с оркестром D-dur (Hob. XIII:1; Hob. XIII:2; Hob. XIII:3), которые композитор создаёт в 1766-1771 годы. При этом обозначение “Ваß” - басовая группа в партитуре концертов и симфоний венского классика - может расшифровываться по-разному: как совместное исполнение партии виолончелью и контрабасом, а также, в зависимости от имеющихся в оркестре в некоторой степени взаимозаменяющихся инструментов. Значительное количество гайдновских концертов, среди которых циклы для клавира, скрипки, виолончели, валторны, флейты с оркестром, написаны для ансамблевооркестровых составов, включающих полную струнную группу с участием альта (2 Violinen, Viola, Baß).

Обращает на себя внимание, что уже в оркестр ранних концертов Й. Гайдном введены духовые инструменты, что соответствует устремлениям композиторов раннеклассического периода. Таков, к примеру, состав первого Концерта для клавира (органа) C-dur (Hob. XVIII:1), который организован по типу раннеклассического оркестра (2 Violinen, Viola, Baß, 2 Oboen, 2 Trompeten). Кроме того, около десяти концертов предполагают участие в ансамблево-оркестровых объединениях деревянных и медных духовых инструментов. Среди них концерты для клавира, скрипки, виолончели, трубы, гобоя с оркестром. Наконец, существуют также образцы, рассчитанные на звучание только струнных и деревянных духовых инструментов. К таковым относятся Концерт для валторны соло D-dur (Hob. VIId:3), включающий 2 Violinen, Viola, Baß, 2 Oboen; Концерт для чембало F-dur (Hob. XVIII:F1), в состав оркестра которого входят 2 Violinen, Viola, Baß, 2 Flöten (два концерта). Группу струнных и медные духовые Й. Гайдн задействует в восьми концертах. Среди них концерты для двух чембало с оркестром G-dur (Hob. XVIII:G2), для скрипки с оркестром A-dur (Hob VIIa:3); для виолончели с оркестром C-dur (Hob. VIIb:1), для двух лир с оркестром C-dur (Hob. VIIh:1), G-dur (Hob. VIIh:2), G-dur (Hob. VIIh:3), F-dur (Hob. VIIh:4), F-dur (Hob. VIIh:5), формируя состав из 2 Violinen, Viola, Baß, 2 Hörnen.

Итак, протяжённый творческий путь Й. Гайдна охватывает обе стадии развития классического оркестра раннеклассическую и собственно направленную на формирование классического парного состава. Обращаясь к партитурам концертов венского классика, отметим, что они преимущественно ориентированы на раннеклассический состав инструментов, характеризующийся своей переменностью, камерным письмом, особенными принципами оркестровки. Гайдновские концерты не замыкаются в собственных рамках, а органично и динамично взаимодействуют как с крупными жанрами - симфониями, операми, ораториями, мессами, кантатами, так и с камерными сонатами, квартетами. Допуская более свободные и смелые эксперименты в выборе инструментария, оркестрово-ансамблевого баланса, они убедительно продолжают развивать свои родовые признаки.

\title{
Список источников
}

1. Аристархова Л. Ю. Австрийская ораториальная традиция XVIII века в оратории Йозефа Гайдна: дисс. ... к. искусствоведения. М., 2006. $221 \mathrm{c.}$

2. Асафьев Б. В. О симфонической и камерной музыке. Л.: Музыка, 1981. 216 с.

3. Вульфиус П. А. Гайдн // Музыкальная энциклопедия: в 6-ти т. / гл. ред. Ю. В. Келдыш. М.: Советская энциклопедия, 1973. Т. 1. А - ГОНГ. Стб. 876-884.

4. Демидова А. К. Оркестровое письмо раннего Гайдна (на материале симфоний 1757-1774 годов): дисс. ... к. искусствоведения. М., 2014. 355 с.

5. Дуков Е. В. Концерт в истории западноевропейской культуры. М.: Классика-XXI, 2003. 256 с.

6. Епишин А. В. Магия музыки барокко: итальянская трио-соната. СПб.: Композитор, 2006. 148 с.

7. Кириллина Л. В. Классический стиль в музыке XVIII - начала XIX века: в 3-х ч. М.: Композитор, 2007. Ч. 3. Поэтика и стилистика. $376 \mathrm{c}$.

8. Прейсман Э. М. Камерный оркестр как явление в музыкальной культуре XVII-XX веков. Красноярск: Красноярский гос. ун-т, 2002. $253 \mathrm{c}$.

9. Шакирьянова А. А. Инструментальные жанры «увеселительной музыки» в австро-немецкой культуре второй половины XVIII века: автореф. дисс. ... к. искусствоведения. Магнитогорск, 2018. 29 с.

10. Hoboken A. von. J. Haydn: Thematisch-bibliographisches Werkverzeichnis: in 3 Bänden. Mainz: Schott, 1957. Bd. 1. 848 S.

\section{J. HAYDN'S INSTRUMENTAL CONCERTS IN THE CONTEXT OF INTER-GENRE INTERACTION}

\author{
Akshentseva Veronika Mikhailovna \\ Magnitogorsk State Conservatory (Academy) named after M. I. Glinka \\ veronikaakshenceva2010@mail.ru
}

The article examines the formation processes of J. Haydn's instrumental concerts in the culturological aspect. The development of the timbre and quantitative instrumental component is analysed in close connection with the music playing practice of that period. The paper considers inter-genre interaction and sociocultural aspects that influenced the genre development. Among them, the author identifies the following ones: musical education, amateur performance, blossom of leisure culture, etc. Crystallization of instrumental groups in J. Haydn's concerts is considered in relation to the practice of ensemble intoning and concerting established in trio sonata and concerto grosso. Instrumental and orchestral compositions of J. Haydn's concerts are examined and classified.

Key words and phrases: concert; music playing; genre; instrumental composition; inter-genre interaction; orchestra; principles of concerting; instrumental colour. 